\title{
ERK1/2 Inhibitor ASN007
}

National Cancer Institute

\section{Source}

National Cancer Institute. ERK1/2 Inhibitor ASN007. NCI Thesaurus. Code C150248.

An orally bioavailable inhibitor of the extracellular signal-regulated kinases 1 (ERK1) and 2 (ERK2), with potential antineoplastic activity. Upon oral administration, ASN007 specifically binds to and inhibits the serine/threonine-protein kinase activities of both ERK1 and ERK2, thereby preventing the phosphorylation of ERK1/2 substrates and the activation of mitogen-activated protein kinase (MAPK)/ERK-mediated signal transduction pathways. This results in the inhibition of ERK-dependent proliferation and survival of tumor cells. The MAPK/ERK pathway, also known as the RAS/RAF/MEK/ERK pathway, is hyperactivated in a variety of tumor cell types due to mutations in upstream targets. It plays a key role in the proliferation, differentiation and survival of tumor cells. 